IZA DP No. 8964

Productivity Effects of Air Pollution: Evidence from Professional Soccer

Andreas Lichter

Nico Pestel

Eric Sommer

April 2015 


\title{
Productivity Effects of Air Pollution: Evidence from Professional Soccer
}

\author{
Andreas Lichter \\ IZA and University of Cologne \\ Nico Pestel \\ IZA and ZEW \\ Eric Sommer \\ IZA and University of Cologne
}
Discussion Paper No. 8964
April 2015

IZA

P.O. Box 7240

53072 Bonn

Germany

Phone: +49-228-3894-0
Fax: +49-228-3894-180
E-mail: iza@iza.org

Any opinions expressed here are those of the author(s) and not those of IZA. Research published in this series may include views on policy, but the institute itself takes no institutional policy positions. The IZA research network is committed to the IZA Guiding Principles of Research Integrity.

The Institute for the Study of Labor (IZA) in Bonn is a local and virtual international research center and a place of communication between science, politics and business. IZA is an independent nonprofit organization supported by Deutsche Post Foundation. The center is associated with the University of Bonn and offers a stimulating research environment through its international network, workshops and conferences, data service, project support, research visits and doctoral program. IZA engages in (i) original and internationally competitive research in all fields of labor economics, (ii) development of policy concepts, and (iii) dissemination of research results and concepts to the interested public.

IZA Discussion Papers often represent preliminary work and are circulated to encourage discussion. Citation of such a paper should account for its provisional character. A revised version may be available directly from the author. 
IZA Discussion Paper No. 8964

April 2015

\section{ABSTRACT}

\section{Productivity Effects of Air Pollution: Evidence from Professional Soccer ${ }^{*}$}

In this paper, we estimate the causal effect of ambient air pollution on individuals' productivity by using panel data on the universe of professional soccer players in Germany over the period 1999-2011. Combining this data with hourly information on the concentration of particulate matter in spatial proximity to each stadium at the time of kickoff, we exploit exogenous variation in the players' exposure to air pollution due to match scheduling rules that are beyond the control of teams and players. Our analysis shows negative and nonlinear effects of air pollution on short-run productivity. We further find that the effect increases with age and is stronger in case players face an additional physical burden.

JEL Classification: J24, Q51, Q53

Keywords: $\quad$ air pollution, productivity, soccer, sports data, Germany

Corresponding author:

Nico Pestel

Institute for the Study of Labor (IZA)

P.O. Box 7240

53072 Bonn

Germany

E-mail: pestel@iza.org

\footnotetext{
*We would like to thank Arnaud Chevalier, Olivier Deschênes, Matthew Gibson, Corrado Giulietti, Dan Hamermesh, Matthew Neidell, Andrew Oswald, Andreas Peichl, Sebastian Siegloch, Konstantinos Tatsiramos, Nicolas Ziebarth as well as participants of the $2^{\text {nd }}$ IZA Workshop on Labor Market Effects of Environmental Policies in Bonn and seminar participants in Bonn (IZA), Mannheim (ZEW) and Luxembourg (CEPS/INSTEAD) for helpful comments and suggestions. Michael Cox and Felix Pöge provided excellent research assistance. The authors are grateful to the data services of the IDSC of IZA and the German Federal Environment Agency.
} 


\section{Introduction}

In recent decades, societies have increasingly become aware of the costs of environmental damage due to unrestrained industrial activity. Nowadays, air pollution is acknowledged as the top environmental risk factor of premature death. In a recent report, the European Environment Agency quantifies annual costs of environmental damage for the European countries to range between 60 and 200 billion Euros, being particularly due to emissions of air pollutants and carbon dioxide (EEA, 2014a b).

Negative effects of air pollution on human health have been well documented in the economics literature (see Graff Zivin and Neidell, 2013, for an overview), emphasizing the trade-off between potential benefits of limiting the emissions of air pollutants and negative impacts on industrial activity and employment! Among others, air pollution has been found to increase morbidity and medical expenditures, as well as to decrease infants' health $2^{2}$ However, negative consequences of environmental damage are not limited to population health, with air pollution impacting the formation of human capital by affecting absenteeism, schooling outcomes or labor supply ${ }^{3}$, and hence triggering long-term consequences for individual earnings (Isen et al., 2014, Lavy et al., 2014a b). Moreover, recent studies, provide evidence that pollution may also reduce workers' short-run productivity and thus hinder economic growth (Graff Zivin and Neidell, 2012; Chang et al., 2014, Li et al., 2015). While these latter findings are of enormous importance for policy makers and the industry, the existing evidence on negative productivity effects of air pollution is to date limited to single-plant case studies using data on low-skilled workers.

In this paper, we contribute to this scarce literature by providing causal estimates of the effect of ambient air pollution on individuals' short-run productivity on a national scale for an entire industry, exploiting information on the universe of

\footnotetext{
${ }^{1}$ Indeed, both the United States and the European Union define regulatory threshold values for air pollution. The limits in the U.S. Clean Air Act (CAA, 1963) and the EU Directive on Ambient Air Quality and Cleaner Air (EU, 2008) are, however, well above the recommended limits of the World Health Organization (WHO, 2006).

${ }^{2}$ See, among others, Schlenker and Walker (2011); Deschênes et al. (2012); Currie et al. (2015) on the effects of air pollution on morbidity and expenditures, and Chay and Greenstone (2003); Currie and Neidell (2005); Currie et al. (2009); Currie and Walker (2011) for studies analyzing the effects of pollution on infants' health and mortality.

${ }^{3}$ See Ransom and Pope (1992); Currie et al. (2009); Hanna and Oliva (2014) for details.
} 
professional soccer players and teams in the German Bundesliga in 2,956 matches and 32 different stadiums throughout the country over a twelve-year period. Professional sports data offer consistent and comparable measures of individuals' short-run productivity (Parsons et al., 2011), which are largely missing for other occupations. We use a player's total number of passes per match as our main measure of productivity and link the data to hourly information on the concentration of particulate matter in spatial proximity to the respective stadium at the hour of kickoff. Due to match scheduling rules that are beyond the control of teams and players, individual exposure to ambient air pollution can be considered as exogenous, offering an ideal setting to overcome endogeneity concerns arising from residential sorting and avoidance behavior.

Our results confirm and extend recent evidence on the negative effects of ambient air pollution on short-run productivity. Using within-player variation in productivity and controlling for weather conditions and the level of ozone concentration at the matchday, as well as a variety of player, team and match variables, we find that a one percent increase in the concentration of particulate matter leads to a 0.02 percent reduction in the number of passes. While this linear effect is small in magnitude, allowing for a non-linear dose-response relationship reveals substantial negative effects: productivity decreases significantly in case the concentration of particulate matter exceeds the EU regulatory threshold of 50 micrograms per cubic meter; the elasticity being -0.16 . Negative effects of pollution are yet also found well below the current limits set by the EU, starting to materialize at around 20 micrograms per cubic meter.

In addition, our analysis points to considerable heterogeneity across individuals. We find that negative effects of pollution on short-run productivity increase with the individuals' age and are largest for players aged above 30. Moreover, midfielders' and defenders' productivity is particularly affected by pollution, players who are more attached to the game and exert a larger number of passes. We further show that the negative effect of ambient air pollution is stronger in case players have less days of rest between matches, while there is weak evidence for adaptation to higher levels of pollution. Our analysis also suggests that players tend to marginally adjust 
their style of play, given that the ratio of long over short passes slightly increases with the concentration of particulate matter.

Overall, our analysis highlights that economic consequences of environmental pollution are not limited to a worsening of population health. High concentrations of particulate matter negatively affect the short-run productivity of professional soccer players to a considerable extent, confirming and extending empirical evidence on negative productivity effects of air pollution for low-skilled workers.

The remainder of this paper is organized as follows. Section II describes the institutional background and the data, while section III introduces the empirical framework and presents the results. Section IV concludes.

\section{Institutional Background and Data}

When estimating the causal effect of air pollution on short-run productivity, researchers face severe empirical challenges (Graff Zivin and Neidell, 2013). Professional soccer provides an ideal setting to overcome these challenges by providing (i) consistent and comparable measures of individuals' productivity, which are hardly available for most other occupations, and (ii) a suitable framework to overcome endogeneity concerns due to self-selection and avoidance behavior. Residential sorting of healthier and more productive individuals into areas with low levels of pollution may bias cross-sectional estimates of the productivity-pollution relationship. Moreover, workers may opt to reduce labor supply on short notice when being subject to high concentrations of air pollutants on a given day.

\section{A Professional Soccer in Germany}

In our analysis, we use exogenous variation in the players' exposure to ambient air pollution due to defined match scheduling rules in the Bundesliga, Germany's top professional league of men's soccer. In every season, it covers 18 teams with each team facing each opponent twice per season, both at home and away. Thus, a season comprises 34 matchdays and 306 matches, typically held on weekends between 
August and May $\left.\right|_{4} ^{4}$ Importantly, match schedules, defining the location, date and time of all matches, are set by the German Football League prior to the beginning of each season and are beyond the control of teams and players. More precisely, the long-term schedule specifies the weekend on which a matchday takes place and which teams face each other at which location. The exact day and time of each match is determined several weeks in advance. 5 Moreover, home and away matches typically alternate by matchday. Thus, even in the very unlikely case of highperforming athletes self-selecting into teams in low-pollution locations, only half of a season's matches are held at the home stadium while away matches are held at stadiums across Germany (see Figure 1). Moreover, avoidance behavior is virtually impossible in the context of the Bundesliga. First, there is no option to reschedule matches. Only in exceptional cases, matches may be canceled on short notice due to extreme weather conditions. Decisions are made by the German Football League or the respective referee. Second, soccer is an outdoor sport, such that, even in the case of awareness, there is no way for players to evade ambient air pollution, which leaves no doubt on players' exposure. Pollution levels at the time of kickoff are thus considered as exogenous to the players and teams, which allows us to estimate the causal effect of pollution on players' productivity.

\section{B Data on Productivity and Pollution}

For the purpose of our analysis, we combine data on individual productivity of professional soccer players in the German Bundesliga with air pollution and meteorological data for the period of 1999 to 2011. Data on individual player productivity is provided by deltatre, a commercial enterprise collecting data on professional sports and serving as an external service provider to the media and sports clubs. The data comprise information on all Bundesliga matches for every season from 1999/2000 to

\footnotetext{
${ }^{4}$ The season is intermitted during winter times, generally from late December to late January. See Figure A.1 for the match schedule's distribution across time. After each season, the worst three teams get relegated, while three teams get promoted from the second division (2. Bundesliga).

${ }^{5}$ The German Football League's scheduling accounts for international soccer competitions and various other marginal conditions. For example, rivaling teams from the same city or neighboring areas do not play matches at home on the same day due to security and local transportation reasons.
} 
2010/2011 and contain detailed information for each match (location, date and kickoff time, home and away teams) and each player, who was on the pitch at some point during the match. For every player, we observe the number of minutes played (up to the full length of 90 minutes), the team played for, the player's position (goalkeeper, defender, midfielder or striker) as well as various measures of productivity.

In our analysis, we use a player's total number of ball passes during a match as our main productivity measure of interest. While the number of passes is not a measure of physical performance per se, it serves as our preferred productivity indicator since it is related to the speed of the game and, importantly, is highly relevant for a team's success by retaining ball possession and creating scoring opportunities. Moreover, passes provide a reliable measure, as passing is the essential nature of the game, which limits the role of chance. $]^{6}$

We combine our data on players' productivity with detailed information from the air pollution monitor system of the German Federal Environment Agency ( Umweltbundesamt). For each match, we extract all available hourly monitor readings for particulate matter smaller than ten micrometers (PM10) and ozone (O3) within a radius of ten kilometers (about 6.2 miles) around the respective stadium at the hour of kickoff and compute inverse-distance weighted means for both pollutants. Matches without pollution readings within this radius are dropped from the sample (716 out of 3,672 ). Throughout our analysis, we focus on the effect of particulate matter while controlling for the level of ozone. We choose this specification for two reasons. First, high levels of particulate matter in ambient air are particularly harmful by entering deep into the lung and affecting the pulmonary and cardiovascular functioning of the human body $]^{7}$ Second, concentration of ozone is most prevalent on days with high temperatures and extensive sunshine. Given that only a limited number of matches are scheduled between June and early August, variation in ozone is limited 8

\footnotetext{
${ }^{6}$ For the English Premier League, Redwood-Brown (2008) shows that the number of completed passes is significantly higher in the five minutes preceding a goal. The number of passes is also correlated with the running distance covered during a match, the correlation being 0.65 for the season of 2013/2014. Note that data on the running distance is only available for this season and obtained from (www.kicker.de), a German soccer magazine's website.

${ }^{7}$ The sports medicine literature provides evidence for a negative relationship between ambient air pollution and performance through particulate matter inhalation (Rundell, 2012).

${ }^{8}$ Alternatively, one could also study the effect of other air pollutants. Particulate matter is yet
} 
Since weather conditions are important environmental confounders of air pollution, we further supplement our dataset with a rich set of weather controls. The data are provided by the German Meteorological Service (Deutscher Wetterdienst) and contain daily information on temperature, precipitation, humidity, air pressure and wind speed. Again, inverse-distance weighted means of all non-missing monitor readings at the matchday in proximity to the stadiums are derived, the radius being 40 kilometers (24.9 miles).

Our final dataset covers twelve seasons (1999/2000 to 2010/2011) and comprises 1,771 individuals playing for 29 different teams in 2,956 matches and on 32 grounds across Germany, totaling to 75,163 player-match observations 9 Descriptive statistics on player characteristics and match conditions are provided in Table 1. Panel A summarizes players' characteristics and measures of productivity. On average, a player passes the ball about 26 times per match, with more than $90 \%$ being short passes (less than 30 meters) and an average accuracy rate of $77 \%$. Professional players in the Bundesliga are young men aged 27 on average, playing for 71 minutes per match and covering the full length (90 minutes) in $58 \%$ of the games played.

On a given matchday, the mean concentration of particulate matter at the time of kickoff is 23.8 micrograms per cubic meter $\left(\mu \mathrm{g} / \mathrm{m}^{3}\right)$, the concentration displaying substantial variation though (see Panel B). In $44 \%$ of the matches covered, we observe a level of PM10 ranging between $20 \mu \mathrm{g} / \mathrm{m}^{3}$ and the EU regulation threshold of $50 \mathrm{\mu g} / \mathrm{m}^{3}$, which is exceeded in $7 \%$ of the matches. Figure 2 plots the variation in PM10 conditional on time and location. Variation in PM10 concentrations is not driven by trends over time, seasonal patterns or certain locations. Rather, we observe substantial variation within years, months and stadiums, highlighting that our identification strategy exploits plausibly exogenous variation in pollution exposure. To be more precise, the left panel of Figure 2 indicates that there is no time trend across seasons; at most, there is a slight reduction in the average concentration in PM10 after 2005 when the EU regulation became binding. The middle panel shows a weak seasonal pattern, with pollution levels being slightly

a very good proxy for air pollution in general, given that it is positively correlated with all other main air pollutants except for ozone (Ziebarth et al. 2013).

${ }^{9}$ Note that we exclude goalkeepers as they constitute a totally different style of play. 
higher during winter months. Last, the right panel provides a ranking of stadiums with respect to the median levels of PM10 concentration, reflecting patterns of population size and density as well as the degree of industrialization in proximity to the stadiums 10

\section{Identifying Pollution Effects on Productivity}

\section{A Empirical Strategy}

Our empirical strategy exploits exogenous variation in players' exposure to pollution.

We use variation in players' productivity over matches and match-level variation in the concentration of particulate matter to derive causal estimates of the effect of pollution on short-run productivity. The underlying empirical model reads:

$$
\ln \left(\mathrm{PASS}_{i m}\right)=\alpha_{i}+\beta \ln \left(\mathrm{PM} 10_{m}\right)+X_{i m}^{\prime} \gamma+W_{m}^{\prime} \delta+M_{m}^{\prime} \mu+\left(T_{t} \times S_{s}\right)+\varepsilon_{i m},
$$

with both the dependent variable, the number of passes of player $i$ in match $m$ $\left(\mathrm{PASS}_{i m}\right)$, as well as the variable of interest, the concentration of particulate matter $\left(\mathrm{PM}_{\mathrm{m}}\right)$, entering our model in logarithmic form. This allows us to interpret the coefficient of interest $(\beta)$ as an elasticity ${ }^{11}$ We control for individual player characteristics such as age, overall tenure, and the minutes and position played in a given match $\left(X_{i m}^{\prime}\right){ }^{12}$ Given that weather conditions are important confounders for air pollution and may also have a direct effect on individuals' productivity Graff Zivin and Neidell, 2013; Adhvaryu et al., 2014), we include controls for the maximum temperature, precipitation, humidity, air pressure and wind speed at a daily level as

\footnotetext{
${ }^{10}$ Figure A.2 shows the broad overlap in the match-by-match variation of PM10 for three selected stadiums, representing high, medium and low average pollution levels, respectively.

${ }^{11}$ We assign zero passes a log value of zero and account for the difference between one and zero passes by means of a corresponding dummy variable. When dropping all observations with zero passes from our sample $(\mathrm{N}=1,331 ; 1.8 \%$ of the sample) our results remain unaffected. Table A.1 in the Appendix presents the corresponding results when a log-level specification of our model is employed. The qualitative results of our analysis are very similar in both specifications.

12 Arguably, the minutes played may be affected by the level of pollution in case coaches selectively substitute at an earlier stage of the game. If this was the case, the variable would be a "bad control". However, the estimates in columns (1) and (2) of Table A.2 show that there is no effect of pollution on the minutes played or on the probability of playing full length in a given match.
} 
well as for ozone concentration at the hour of kickoff observed in spatial proximity to the stadium for a given match $\left(W_{m}^{\prime}\right)$. Moreover, we account for features of the particular game: the time and weekday of kickoff and stadium attendance $\left(M_{m}^{\prime}\right)$. Lastly, we add team-season fixed effects $\left(T_{t} \times S_{s}\right)$ to capture all factors that are specific to a team within a season, such as the squad's composition and quality, the team's style of play and the club's budget, and add player fixed effects to control for unobserved time-invariant differences across players $\left(\alpha_{i}\right)$. Identification of our model thus relies on the exogenous variation in players' exposure to pollution at different stadiums over time. As our research design exposes players to different locations and different levels of pollution at every matchday, we cluster standard errors at the player level ${ }^{13}$

We acknowledge that player $i$ 's productivity might be a function of his teammates' and opponents' productivity, which is also affected by pollution. Whereas negative effects of pollution on opponents' performance should bias our estimates towards zero (as it becomes easier to pass), the opposite may be true for the effect of pollution on teammates' performance. To account for this potential concern, we additionally estimate equation (1) at the team and match level, respectively. Interaction effects between pollution, the individual $i^{\prime} s$ and his teammates' and/or opponents' productivity are explicitly accounted for at these aggregate levels. As shown below, individual-level and team-/match-level estimates are of similar magnitude, suggesting that both channels either cancel out or are of minor importance.

\section{B Estimates of Air Pollution on Productivity}

Baseline estimates. We begin our analysis by examining the linear effect of exposure to PM10 concentration on players' performance. Table 2 displays the corresponding results. ${ }^{14}$ In column (1), we present the results when applying simple OLS, while controlling for player characteristics only. We find a statistically significant

\footnotetext{
13 Note that our research design does not allow for clustering at the stadium level given that players do perform at different stadiums. Clustering standard errors at the team level is feasible in case excluding all players from our analysis that play for different Bundesliga teams during their career. As this holds true for $30 \%$ of our sample, we yet abstain from clustering at the team level.

${ }^{14}$ For the sake of clarity, we abstain from reporting the coefficients on the full set of control variables. Detailed regression outputs are available from the authors upon request.
} 
negative, albeit small, effect of air pollution on players' productivity, with a point estimate of -0.018 . In column (2), we add player-fixed effects to our model, thus identify the effect of air pollution on productivity by using within-player variation only. The estimated coefficient remains statistically significant and of similar magnitude, suggesting that there is no systematic selection of players with respect to the degree of air pollution on matchdays (see Graff Zivin and Neidell, 2012, for similar reasoning). In columns (3) to (5), we subsequently include weather and further match-level controls as well as team-season fixed effects. Results are very robust to the inclusion of additional controls. The results of our preferred specification (column 5) show a statistically significant elasticity between the concentration of PM10 and the number of passes of -0.02 , which means that an increase by $1 \%$ in PM10 reduces the number of passes by $0.02 \% .15$ Lastly, we add stadium fixed effects to our model. Column (6) shows that the inclusion of stadium fixed effects hardly changes our estimate. As this specification limits variation in PM10 to home matches within a season, we yet abstain from controlling for stadium fixed effects hereafter 16

Non-linear effects. We next test for a non-linear dose-response relationship between the concentration of particulate matter and player productivity, results being presented in Table 3. In column (1), we specify a quadratic relationship between pollution and productivity. Indeed, we find that pollution has stronger negative effects on productivity at high levels of PM10 concentration. In columns (2) to (4), we also allow for flexible non-linear functional forms by interacting the main effect of PM10 with various threshold values. Column (2) shows that pollution affects productivity in case the concentration of PM10 exceeds $20 \mu \mathrm{g} / \mathrm{m}^{3}$, while there is no significant effect below that level. Moreover, effects are particularly strong in case pollution levels exceed the EU limit value of $50 \mu \mathrm{g} / \mathrm{m}^{3}$, the respective elasticity being -0.14 (column 3). Finally, we model the relationship between PM10 and passes to be piecewise linear. Corresponding to the results displayed in columns (2) and (3), column (4) shows that the effect of ambient air pollution is strongest

\footnotetext{
15 The result is slightly stronger for the number of short passes, see column (3) of Table A.2.

16 Recall that each team faces each opponent twice per season, both at home and away. The only exception are players that change teams during a season (around 1.4\%).
} 
above $50 \mu \mathrm{g} / \mathrm{m}^{3}$, the elasticity being close to -0.16 . Moreover, whereas there is no impact below the level of $20 \mu \mathrm{g} / \mathrm{m}^{3}$, we find a significant albeit moderate effect for concentrations ranging between 20 and $50 \mu \mathrm{g} / \mathrm{m}^{3}$, levels well below the EU limit ${ }^{17}$

Effects by player characteristics. We further investigate heterogeneous effects of ambient air pollution on productivity among different types of players. Although professional soccer players constitute a rather homogeneous group, we account for different effects by players' age and position. Given that we do not observe individual players' health and that professional athletes are in very good shape, we use age as a proxy for the human body's physiological condition, assuming that players become more sensitive to pollution when becoming older. In addition, we split our sample by players' position to investigate whether the effect of pollution depends on the player's general physical burden in the game ${ }^{18}$

Columns (1) and (2) of Table 4 show the corresponding results when interacting the PM10 concentration with players' age. We find no significant effect for young players (below age 21), whereas productivity of more senior players decreases with the level of pollution. When accounting for differential effects of pollution by players' position, we find that pollution significantly affects the productivity of midfielders and defenders, but not of strikers. This is consistent with the notion that defenders and midfielders exhibit more physically burdensome tasks and take a more active role than strikers. Indeed, defenders and midfielders pass significantly more often than strikers (32.7 and 26.9 vs. 15.7 passes per match), suggesting that pollution affects productivity of workers with more burdensome tasks to a larger extent.

Effects by match characteristics. Having provided evidence on differential effects across types of players, we further investigate whether the effect of air pollution on productivity depends on characteristics of the match. First, we test whether there is a differential effect for the home team's players, given that they might have accus-

\footnotetext{
${ }^{17}$ In Figure A.3, we visualize the effect of PM10 on productivity when modeling the underlying relationship using a series of $10 \mu \mathrm{g} / \mathrm{m}^{3}$ indicator bins.

18 Although we control for the position of each player in our baseline specification, a player's position is generally set for an entire season, if not career. Changes in players' positions are infrequent such that we split the sample accordingly.
} 
tomed to the average pollution levels at the home stadium. However, as displayed in column (1) of Table 5, we find no evidence for adaptation to local pollution levels.

Next, we analyze whether the negative effect of pollution on productivity becomes stronger in case players' physical strain increases. First, we interact the level of PM10 with a dummy variable indicating whether a player's teammate has been sent off during a game due to violation of the rules. Arguably, the remaining players need to exert more effort in case of being outnumbered. At least one player has been sent off in around $9 \%$ of the matches covered. Second, we investigate whether the effect of pollution increases with the overall intensity of the game. Therefore, we analyze the effect of pollution on players' productivity in matches that can be assumed to be more intense compared to others a priori. We classify matches to be more intense in case two teams meet at a given matchday that are of equal strength within a season, with the total number of points earned by each team differing by three or less points after matchday ten. According to this definition, around $16 \%$ of the games are labeled as high-intensity matches. Third, we analyze whether less days of rest between two matches increases the negative effect of pollution on productivity. We create a binary variable that indicates whether a team has had less than five days of rest, which is due to matches scheduled during the week 19

Overall, our results provide evidence that negative effects of pollution on productivity intensify in case the physical burden of players increases. As displayed in column (2) of Table 5, we find that increases in the physical burden due to a reduction in the number of teammates strengthens the negative effect of pollution on productivity, the effect being insignificant at conventional levels though ( $\mathrm{p}$-value $=$ 0.114). From columns (3) and (4) we yet infer that the effect of PM10 increases significantly in case matches are intense or players had less days of rest. Compared to a baseline elasticity of -0.018 , the point estimates increase to -0.031 and -0.030 in case matches are of high intensity and players had less than five days of rest, respectively.

${ }^{19}$ Note that Bundesliga matches are occasionally held during the week. Beyond, all Bundesliga teams participate in the national cup (DFB-Pokal), a tournament with direct elimination. Moreover, teams finishing a season among the top five to seven teams qualify for competitions at the European level in the subsequent season, either the Champions League or the Europa League. 
Lagged effects and adaptation. So far, we have shown that the concentration of PM10 in ambient air has an immediate and negative effect on players' productivity. Although we find no adaptation to the average pollution level at the player's home base (see column (1) of Table 4), we next investigate whether the relevant duration of exposure to air pollution may be longer than a few hours on a particular matchday and whether individuals may temporarily adjust to increases in pollution.

Testing for effects of lagged exposure and potential adaptation requires information on individuals' ambient air pollution exposure prior to the matchday. While our data only contains information on the dates and locations of matches, we are able to construct lagged pollution exposure by collecting information on the location of teams' training grounds. We combine this information with data from the pollution monitor system and assign the average level of PM10 concentration on the two days preceding a match to each player ${ }^{20}$ This procedure is based on the plausible assumption that players spend most of the time outdoors exercising with their teams on the days before a match. We include this variable in our baseline regression model (1) and interact it with the contemporaneous level of pollution. Formally, the empirical model expands to:

$$
\begin{aligned}
\ln \left(\mathrm{PASS}_{i m}\right) & =\alpha_{i}+\beta_{1} \ln \left(P M 10_{m}\right)+\beta_{2} \ln \left(P M 10_{m t}^{\text {lag }}\right) \\
& +\beta_{3} \ln \left(P M 10_{m}\right) \times \ln \left(P M 10_{m t}^{\text {lag }}\right) \\
& +X_{i m}^{\prime} \gamma+W_{m}^{\prime} \delta+M_{m}^{\prime} \mu+\left(T_{t} \times S_{s}\right)+\varepsilon_{i m},
\end{aligned}
$$

with $P M 10_{m t}^{\text {ag }}=\frac{1}{2} \sum_{\tau=1}^{2} P M 10_{m t}^{d a y-\tau}$. Here, coefficient $\beta_{1}$ captures the contemporaneous effect of pollution, $\beta_{2}$ provides the lagged effect of PM10 exposure, while $\beta_{3}$ informs about adaptation, i.e., whether players' lagged exposure affects the contemporaneous impact of PM10 concentration. The corresponding results are presented in Table $6{ }^{21}$ We find that the contemporaneous effect of pollution is not significantly different from our baseline estimate given in column (5) of Table 2. Moreover, we show that the estimate for the lagged effect is smaller in magnitude, but also statis-

\footnotetext{
20 The lagged pollution level is derived in the same way as the pollution levels for each stadium at the time of kickoff, using an inverse-distance weighted mean of daily PM10 levels.

${ }^{21}$ Note that the number of observations decreases slightly compared to our baseline specification as pre-match data on pollution levels and weather conditions are missing in some cases.
} 
tically significant and negative. We take this finding as evidence for longer lasting effects of pollution on productivity. Finally, in column (6) of Table 6 we additionally include the interaction term between contemporaneous and lagged pollution. The estimate for $\beta_{3}$ is small, but marginally significant and positive, which implies that players indeed slightly adjust to high levels of pollution on pre-match days.

Effects on team and match level. By now, our analysis has been conducted on the player level, exploiting variation in the number of passes of each player over time. However, as mentioned before, we might miss important interactions within a player's team and/or with the opponent when using variation at the player level. Hence, we test whether pollution affects the aggregate number of passes at the team and match level, controlling for weather conditions, season fixed effects as well as aggregate player characteristics. Displayed in Table 7, we find that team and match level estimates are very much in line with our baseline results. Hence, interaction effects between pollution, the individual's and his teammates' and/or opponents' productivity may either cancel out or be of small magnitude.

Effects on pass accuracy and pass ratio. We further analyze the effect of pollution on additional indicators that are typically used to evaluate player or team productivity and are also more related to the ability to concentrate and the style of play. One indicator of interest is the player's pass accuracy, indicating ball possession and leading to scoring opportunities (Redwood-Brown, 2008; Oberstone, 2009). As displayed in column (3) of Table A.2, we find a statistically significant, albeit tiny, effect. We further test whether players adjust their style of play when being exposed to high levels of pollution. Therefore, we test whether the ratio of long and short passes is affected by pollution. We argue that while passing the ball over longer distances is more risky in terms of retaining ball possession, it may reduce the overall physical burden. However, as displayed in column (4) of Table A.2, we find that pollution hardly affects this ratio. 


\section{Conclusion}

In this paper, we estimate the causal effect of ambient air pollution on individuals' productivity. Using panel data on the universe of soccer players in the German Bundesliga and hourly information on the concentration of particulate matter in spatial proximity to the stadium at the hour of kickoff, we exploit exogenous variation in the players' exposure to air pollution due to match scheduling rules.

Our results show that air pollution, measured by the concentration of particulate matter, has a negative effect on productivity. While the baseline linear effect is statistically significant and robust, the magnitude is quite small. However, when allowing for a non-linear dose-response relationship, substantial negative effects are found: productivity decreases significantly in case the concentration of particulate matter exceeds the EU regulatory threshold of 50 micrograms per cubic meter; the elasticity being -0.16 . Negative effects of pollution are yet also found well below the current limits set by the EU, starting to materialize at around 20 micrograms per cubic meter. Accounting for heterogeneity across players, we further find that the overall effect is mainly driven by players of relatively older age and those positions that require more effort. Moreover, additional physical burden exacerbates pollution's impact on productivity.

Our analysis highlights that economic consequences of environmental pollution are not limited to adverse impacts on population health. Even moderate concentrations of particulate matter commonly experienced in developed countries negatively affect the productivity of a selective group of professional soccer players, young and male athletes, to a considerable extent. Our findings hence complement previous empirical evidence on air pollution's negative effects on the productivity of low-skilled agricultural and factory workers in countries with higher levels of pollution Graff Zivin and Neidell, 2012; Chang et al., 2014; Li et al., 2015). While our data allows us to consistently measure individuals' productivity for an entire industry and over multiple years, it remains unclear to what extent our findings can be generalized to the wider labor force. Future research on more representative groups of workers should further examine the effect of pollution on physical and cognitive productivity and broaden our knowledge on the benefits of environmental regulation. 


\section{References}

Adhvaryu, A., N. Kala, and A. Nyshadham (2014). The Light and the Heat: Productivity Co-benefits of Energy-saving Technology. Unpublished Manuscript.

CAA (1963). United States Clean Air Act of 1963.

Chang, T., J. Graff Zivin, T. Gross, and M. Neidell (2014). Particulate Pollution and the Productivity of Pear Packers. NBER Working Paper No. 19944.

Chay, K. Y. and M. Greenstone (2003). The Impact of Air Pollution on Infant Mortality: Evidence from Geographic Variation in Pollution Shocks Induced by a Recession. Quarterly Journal of Economics 118(3), 1121-1167.

Currie, J., L. Davis, M. Greenstone, and R. Walker (2015). Environmental Health Risks and Housing Values: Evidence from 1,600 Toxic Plant Openings and Closings. American Economic Review 105(2), 678-709.

Currie, J., E. A. Hanushek, E. M. Kahn, M. Neidell, and S. G. Rivkin (2009). Does Pollution Increase School Absences? Review of Economics and Statistics 91(4), 682-694.

Currie, J. and M. Neidell (2005). Air Pollution and Infant Health: What Can We Learn from California's Recent Experience? Quarterly Journal of Economics 120(3), 1003-1030.

Currie, J., M. Neidell, and J. F. Schmieder (2009). Air pollution and infant health: Lessons from New Jersey. Journal of Health Economics 28, 688-703.

Currie, J. and R. Walker (2011). Traffic Congestion and Infant Health: Evidence from E-ZPass. American Economic Journal: Applied Economics 3, 65-90.

Deschênes, O., M. Greenstone, and J. S. Shapiro (2012). Defensive Investments and the Demand For Air Quality: Evidence From the NOx Budget Program and Ozone Reductions. NBER Working Paper No. 18267.

EEA (2014a). European Environment Agency: Air Quality in Europe - 2014 Report. EEA Report No. 5/2014.

EEA (2014b). European Environment Agency: Costs of Air Pollution from European Industrial Facilities 2008-2012 - An Updated Assesment. EEA Technical Report No. 20/2014.

EU (2008). Directive 2008/50/EC of the European Parliament and of the Council of 21 May 2008 on Ambient Air Quality and Cleaner Air for Europe. Official Journal L 152, 11.6.2008, 1-44.

Graff Zivin, J. and M. Neidell (2012). The Impact of Pollution on Worker Productivity. American Economic Review 102(7), 3652-3673.

Graff Zivin, J. and M. Neidell (2013). Environment, Health, and Human Capital. Journal of Economic Literature 51(3), 689-730. 
Hanna, R. and P. Oliva (2014). The Effect of Pollution on Labor Supply: Evidence from a Natural Experiment in Mexico City. Journal of Public Economics, forthcoming.

Isen, A., M. Rossin-Slater, and R. Walker (2014). Every Breath You Take - Every Dollar You'll Make: The Long-Term Consequences of the Clean Air Act of 1970. NBER Working Paper No. 19858.

Lavy, V., A. Ebenstein, and S. Roth (2014a). The Impact of Short Term Exposure to Ambient Air Pollution on Cognitive Performance and Human Capital Formation. NBER Working Paper No. 20648.

Lavy, V., A. Ebenstein, and S. Roth (2014b). The Long Run Human Capital and Economic Consequences of High-Stakes Examinations. NBER Working Paper No. 20647.

Li, T., H. Liu, and A. Salvo (2015). Severe Air Pollution and Labor Productivity. IZA Discussion Paper No. 8916.

Oberstone, J. (2009). Differentiating the Top English Premier League Football Clubs from the Rest of the Pack: Identifying the Keys to Success. Journal of Quantitative Analysis in Sports 5(3), 10.

Parsons, C. A., J. Sulaeman, M. C. Yates, and D. S. Hamermesh (2011). Strike Three: Discrimination, Incentives, and Evaluation. American Economic Review 101(4), 1410-1435.

Ransom, M. R. and C. A. Pope (1992). Elementary School Absences and PM10 Pollution in Utah Valley. Environmental Research 58(1-2), 204-219.

Redwood-Brown, A. (2008). Passing Patterns Before and After Goal Scoring in FA Premier League Soccer. International Journal of Performance Analysis in Sport 8(3), 172-182.

Rundell, K. W. (2012). Effect of Air Pollution on Athlete Health and Performance. British Journal of Sports Medicine 46, 407-412.

Schlenker, W. and W. R. Walker (2011). Aiports, Air Pollution, and Contemporaneous Health. NBER Working Paper No. 17684.

WHO (2006). World Health Organization: Air Quality Guidelines for Particulate Matter, Ozone, Nitrogen Dioxide and Sulfur Dioxide - Global Update 2005.

Ziebarth, N. R., M. Schmitt, and M. Karlsson (2013). The Short-Term Population Health Effects of Weather and Pollution: Implications of Climate Change. IZA Discussion Paper No. 7875. 


\section{Figures and Tables}

Figure 1: Geographic distribution of stadiums across Germany

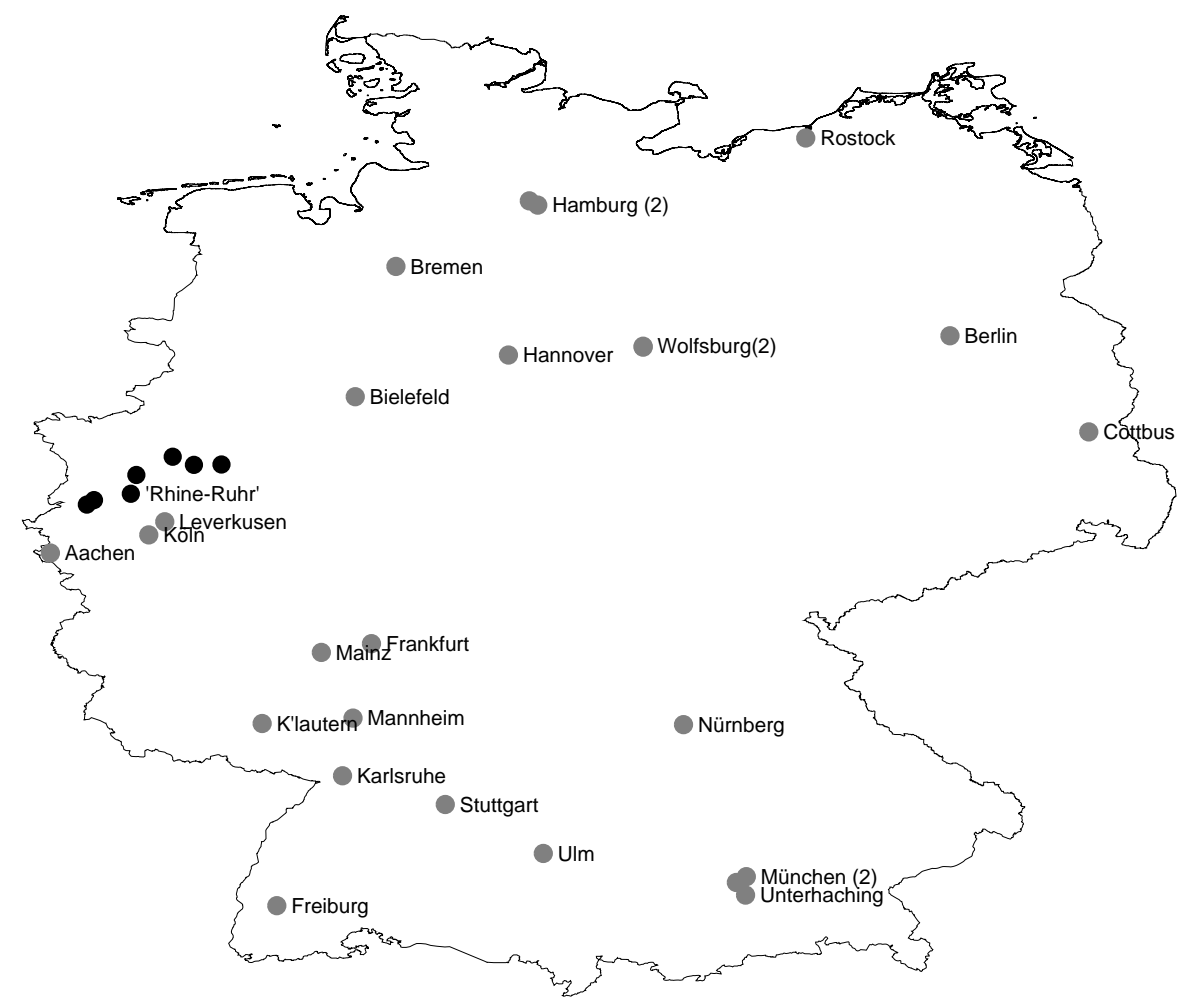

Note: This map shows the geographical location of Bundesliga stadiums in our sample across Germany, indicated by the respective city names. The number of stadiums located in one city is indicated in brackets. The black dots indicate cities in the Rhine-Ruhr Area and comprise (from west to east) the stadiums in Mönchengladbach (2), Düsseldorf, Duisburg, Gelsenkirchen, Bochum and Dortmund. 
Figure 2: Variation of particulate matter across matches
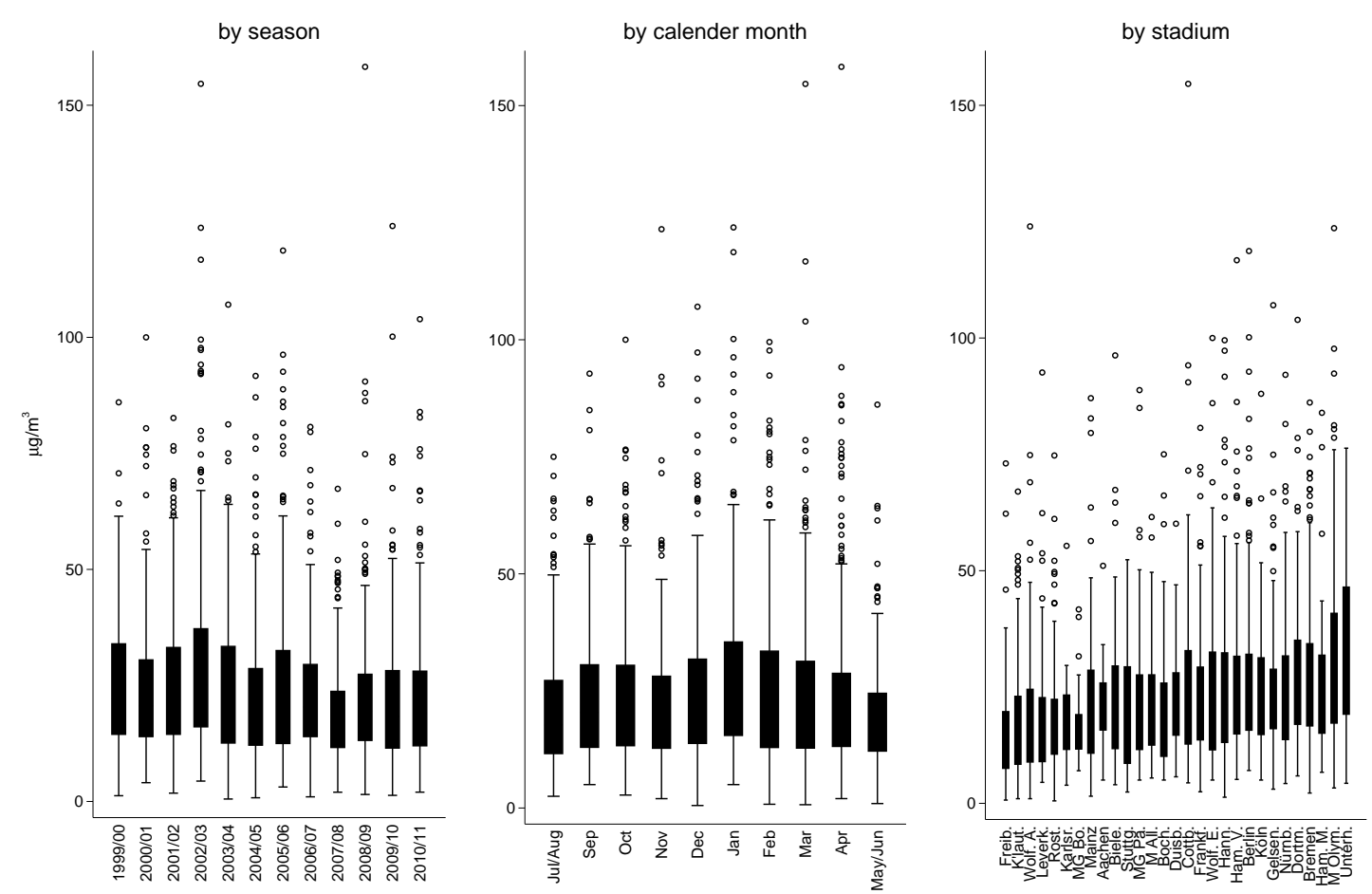

Note: This graph shows boxplot charts visualizing the variation of particulate matter (PM10) at the hour of match kickoffs over time by seasons (left panel), over the year by calender months (middle panel) and across different stadiums (right panel). Measurements in July and June are merged with August and May respectively, since only very few matches were held during the two summer months. Stadiums with less than ten match observations are excluded from this graph. 
Table 1: Summary statistics on player and match level variables

\begin{tabular}{|c|c|c|c|c|c|c|}
\hline Variable & Mean & Std. Dev. & Median & Min. & Max. & Obs. \\
\hline & \multicolumn{6}{|c|}{ Panel A: Player-level Data } \\
\hline \multicolumn{7}{|l|}{ Player productivity } \\
\hline Total passes & 26.3 & 16.48 & 25 & 0 & 138 & 75,163 \\
\hline Short passes & 23.95 & 15.06 & 23 & 0 & 123 & 75,163 \\
\hline Pass rate (completed over total) & .77 & .15 & .79 & 0 & 1 & 73,832 \\
\hline Pass ratio (long over short) & .1 & .15 & .06 & 0 & 6 & 73,718 \\
\hline \multicolumn{7}{|l|}{ Player characteristics } \\
\hline Age (years) & 26.81 & 3.93 & 26.71 & 16.92 & 39.55 & 75,163 \\
\hline Tenure (matches for team) & 51.22 & 52.08 & 34 & 1 & 390 & 75,163 \\
\hline Minutes played & 70.6 & 28.97 & 90 & 1 & 90 & 75,163 \\
\hline Played full length (1=yes) & .58 & .49 & 1 & 0 & 1 & 75,163 \\
\hline & \multicolumn{6}{|c|}{ Panel B: Match-level Data } \\
\hline \multicolumn{7}{|l|}{ Pollution measures (hourly basis) } \\
\hline PM10 $\left(\mu g / m^{3}\right)$ & 23.76 & 16.22 & 20.05 & .53 & 158.28 & 2,956 \\
\hline Log of PM10 & 2.96 & .68 & 3 & -.64 & 5.06 & 2,956 \\
\hline PM10 <20 (1=yes) & .5 & .5 & 0 & 0 & 1 & 2,956 \\
\hline PM10 [20-50] (1=yes) & .44 & .5 & 0 & 0 & 1 & 2,956 \\
\hline PM10 >50 (1=yes) & .07 & .25 & 0 & 0 & 1 & 2,956 \\
\hline Ozone $\left(\mu \mathrm{g} / \mathrm{m}^{3}\right)$ & 55.06 & 34.27 & 53.21 & .13 & 248 & 2,956 \\
\hline \multicolumn{7}{|l|}{ Weather controls (daily basis) } \\
\hline$\overline{\text { Maximum temperature }\left({ }^{\circ} \mathrm{C}\right)}$ & 12.59 & 7.6 & 12.35 & -12.16 & 36.06 & 2,956 \\
\hline Precipitation $\left(\mathrm{mm} / \mathrm{m}^{2}\right)$ & 1.97 & 3.81 & .2 & 0 & 34.03 & 2,956 \\
\hline Dewpoint $\left({ }^{\circ} C\right)$ & 4.47 & 5.69 & 4.55 & -16.95 & 18.79 & 2,956 \\
\hline Air pressure $(h P a)$ & 993.3 & 22.64 & 999.07 & 924.88 & $1,044.7$ & 2,956 \\
\hline Wind speed $(\mathrm{m} / \mathrm{sec})$ & 3.61 & 1.84 & 3.2 & .8 & 16.6 & 2,956 \\
\hline \multicolumn{7}{|l|}{ Other controls } \\
\hline Stadium attendance $(1,000 \mathrm{~s})$ & 38.34 & 17.18 & 36.09 & 6 & 83 & 2,956 \\
\hline
\end{tabular}


Table 2: Effect of particulate matter on players' productivity

\begin{tabular}{|c|c|c|c|c|c|c|}
\hline & \multirow{2}{*}{$\begin{array}{c}\begin{array}{c}\text { Pooled } \\
\text { OLS }\end{array} \\
(1)\end{array}$} & \multicolumn{5}{|c|}{ Player fixed effects } \\
\hline & & $(2)$ & $(3)$ & $(4)$ & (5) & (6) \\
\hline $\ln (\mathrm{PM} 10)$ & $\begin{array}{c}-0.018^{* * *} \\
(0.002)\end{array}$ & $\begin{array}{c}-0.015^{* * *} \\
(0.002)\end{array}$ & $\begin{array}{c}-0.020^{* * *} \\
(0.003)\end{array}$ & $\begin{array}{c}-0.018^{* * *} \\
(0.003)\end{array}$ & $\begin{array}{c}-0.020^{* * *} \\
(0.003)\end{array}$ & $\begin{array}{c}-0.015^{* * *} \\
(0.003)\end{array}$ \\
\hline Player characteristics & Yes & Yes & Yes & Yes & Yes & Yes \\
\hline Weather and ozone controls & No & No & Yes & Yes & Yes & Yes \\
\hline Match controls & No & No & No & Yes & Yes & Yes \\
\hline Team $\times$ Season FE & No & No & No & No & Yes & Yes \\
\hline Stadium FE & No & No & No & No & No & Yes \\
\hline Observations & 75,163 & 75,163 & 75,163 & 75,163 & 75,163 & 75,163 \\
\hline Adjusted R-Squared & 0.770 & 0.746 & 0.746 & 0.747 & 0.753 & 0.756 \\
\hline
\end{tabular}

Note: Dependent variable: Log of passes. Player characteristics: age (squared), tenure (squared), position dummies, minutes played (squared). Weather and ozone controls: maximum temperature (in 5 degree Celsius indicator bins), precipitation (in $5 \mathrm{~mm} / \mathrm{m}^{2}$ indicator bins), dew point (in 5 degree Celsius indicator bins), wind speed (in 2.5 $\mathrm{m} / \mathrm{sec}$ indicator bins), air pressure (in $25 \mathrm{hPa}$ indicator bins) and ozone concentration (in $20 \mu \mathrm{g} / \mathrm{m}^{3}$ indicator bins). Weather indicators are daily averages, ozone is measured at the hour of kickoff. Match controls: day of week, kickoff time and stadium attendance indicators. Significance levels are $0.1\left(^{*}\right), 0.05\left({ }^{* *}\right)$, and $0.01\left(^{* * *}\right)$.

Table 3: Non-linear effect of particulate matter on players' productivity

\begin{tabular}{|c|c|c|c|c|}
\hline & \multicolumn{4}{|c|}{ Player fixed effects } \\
\hline & (1) & $(2)$ & (3) & (4) \\
\hline $\ln (\mathrm{PM} 10)$ & $\begin{array}{c}0.024^{* *} \\
(0.012)\end{array}$ & $\begin{array}{c}0.000 \\
(0.004)\end{array}$ & $\begin{array}{c}-0.020^{* * *} \\
(0.003)\end{array}$ & $\begin{array}{c}0.000 \\
(0.001)\end{array}$ \\
\hline $\ln (\mathrm{PM} 10) \times \ln (\mathrm{PM} 10)$ & $\begin{array}{c}-0.008^{* * *} \\
(0.002)\end{array}$ & & & \\
\hline $\ln (\mathrm{PM} 10) \times(\mathrm{PM} 10>20)$ & & $\begin{array}{c}-0.020^{* * *} \\
(0.008)\end{array}$ & & \\
\hline $\ln (\mathrm{PM} 10) \times(\mathrm{PM} 1020-50)$ & & & & $\begin{array}{c}-0.019^{*} \\
(0.010)\end{array}$ \\
\hline $\ln (\mathrm{PM} 10) \times(\mathrm{PM} 10>50)$ & & & $\begin{array}{c}-0.137^{* * *} \\
(0.025)\end{array}$ & $\begin{array}{c}-0.158^{* * *} \\
(0.025)\end{array}$ \\
\hline Player characteristics & Yes & Yes & Yes & Yes \\
\hline Weather and ozone controls & Yes & Yes & Yes & Yes \\
\hline Match controls & Yes & Yes & Yes & Yes \\
\hline Team $\times$ Season FE & Yes & Yes & Yes & Yes \\
\hline Observations & 75,163 & 75,163 & 75,163 & 75,163 \\
\hline Adjusted R-Squared & 0.739 & 0.740 & 0.740 & 0.740 \\
\hline
\end{tabular}

Note: Dependent variable: Log of passes. Player characteristics: age (squared), tenure (squared), position dummies, minutes played (squared). Weather and ozone controls: maximum temperature (in 5 degree Celsius indicator bins), precipitation (in $5 \mathrm{~mm} / \mathrm{m}^{2}$ indicator bins), dew point (in 5 degree Celsius indicator bins), wind speed (in 2.5 $\mathrm{m} / \mathrm{sec}$ indicator bins), air pressure (in $25 \mathrm{hPa}$ indicator bins) and ozone concentration (in $20 \mathrm{\mu g} / \mathrm{m}^{3}$ indicator bins). Weather indicators are daily averages, ozone is measured at the hour of kickoff. Match controls: day of week, kickoff time and stadium attendance indicators. Significance levels are $0.1\left(^{*}\right), 0.05(* *)$, and $0.01(* * *)$. 
Table 4: Effect of particulate matter on productivity by player characteristics

\begin{tabular}{|c|c|c|c|c|c|}
\hline & \multicolumn{2}{|c|}{ Full sample } & \multirow{2}{*}{$\frac{\text { Midfielder }}{(3)}$} & \multirow{2}{*}{$\frac{\text { Defender }}{(4)}$} & \multirow{2}{*}{$\frac{\text { Striker }}{(5)}$} \\
\hline & (1) & $(2)$ & & & \\
\hline $\ln (\mathrm{PM} 10)$ & $\begin{array}{c}0.017 \\
(0.016)\end{array}$ & & $\begin{array}{c}-0.022^{* * *} \\
(0.004)\end{array}$ & $\begin{array}{c}-0.025^{* * *} \\
(0.005)\end{array}$ & $\begin{array}{l}-0.008 \\
(0.006)\end{array}$ \\
\hline $\ln (\mathrm{PM} 10) \times$ age & $\begin{array}{c}-0.001^{* *} \\
(0.001)\end{array}$ & & & & \\
\hline $\ln ($ PM10 $) \times($ aged $<21)$ & & $\begin{array}{l}-0.001 \\
(0.010)\end{array}$ & & & \\
\hline $\ln ($ PM10 $) \times($ aged $21-25)$ & & $\begin{array}{c}-0.017^{* * *} \\
(0.004)\end{array}$ & & & \\
\hline $\ln ($ PM10 $) \times($ aged $26-30)$ & & $\begin{array}{c}-0.022^{* * *} \\
(0.004)\end{array}$ & & & \\
\hline $\ln ($ PM10 $) \times($ aged $>30)$ & & $\begin{array}{c}-0.031^{* * *} \\
(0.006)\end{array}$ & & & \\
\hline Player characteristics & Yes & Yes & Yes & Yes & Yes \\
\hline Weather and ozone controls & Yes & Yes & Yes & Yes & Yes \\
\hline Match controls & Yes & Yes & Yes & Yes & Yes \\
\hline Team $\times$ Season FE & Yes & Yes & Yes & Yes & Yes \\
\hline Observations & 75,163 & 75,163 & 34,023 & 24,471 & 16,669 \\
\hline Adjusted R-Squared & 0.739 & 0.739 & 0.778 & 0.561 & 0.764 \\
\hline
\end{tabular}

Note: Dependent variable: Log of passes. Player characteristics: age (squared), tenure (squared), position dummies, minutes played (squared). Weather and ozone controls: maximum temperature (in 5 degree Celsius indicator bins), precipitation (in $5 \mathrm{~mm} / \mathrm{m}^{2}$ indicator bins), dew point (in 5 degree Celsius indicator bins), wind speed (in 2.5 $\mathrm{m} / \mathrm{sec}$ indicator bins), air pressure (in $25 \mathrm{hPa}$ indicator bins) and ozone concentration (in $20 \mathrm{\mu g} / \mathrm{m}^{3}$ indicator bins). Weather indicators are daily averages, ozone is measured at the hour of kickoff. Match controls: day of week, kickoff time and stadium attendance indicators. Significance levels are $0.1(*), 0.05(* *)$, and $0.01(* * *)$.

Table 5: Effect of particulate matter on productivity by match characteristics

\begin{tabular}{|c|c|c|c|c|}
\hline & \multicolumn{4}{|c|}{ Player fixed effects } \\
\hline & (1) & $(2)$ & $(3)$ & $(4)$ \\
\hline $\ln (\mathrm{PM} 10)$ & $\begin{array}{c}-0.020^{* * *} \\
(0.004)\end{array}$ & $\begin{array}{c}-0.020^{* * *} \\
(0.003)\end{array}$ & $\begin{array}{c}-0.018^{* * *} \\
(0.003)\end{array}$ & $\begin{array}{r}-0.018^{* * *} \\
(0.003)\end{array}$ \\
\hline $\ln ($ PM10 $) \times($ home team $)$ & $\begin{array}{c}0.001 \\
(0.004)\end{array}$ & & & \\
\hline $\ln ($ PM10 $) \times($ player sent off $)$ & & $\begin{array}{l}-0.013 \\
(0.008)\end{array}$ & & \\
\hline $\ln ($ PM10 $) \times($ high-intensity match $)$ & & & $\begin{array}{c}-0.013^{* *} \\
(0.006)\end{array}$ & \\
\hline $\ln ($ PM10 $) \times($ less days of rest $)$ & & & & $\begin{array}{c}-0.012^{* *} \\
(0.005)\end{array}$ \\
\hline Player characteristics & Yes & Yes & Yes & Yes \\
\hline Weather and ozone controls & Yes & Yes & Yes & Yes \\
\hline Match controls & Yes & Yes & Yes & Yes \\
\hline Team $\times$ Season FE & Yes & Yes & Yes & Yes \\
\hline Observations & 75,163 & 75,163 & 75,163 & 75,163 \\
\hline Adjusted R-Squared & 0.741 & 0.740 & 0.739 & 0.739 \\
\hline
\end{tabular}

Note: Dependent variable: Log of passes. High-intensity matches are defined by the point difference being $\leq 3$ before the match after matchday ten. Less of days of rest indicates that the team had a match less than five days before. Player characteristics: age (squared), tenure (squared), position dummies, minutes played (squared). Weather and ozone controls: maximum temperature (in 5 degree Celsius indicator bins), precipitation (in $5 \mathrm{~mm} / \mathrm{m}^{2}$ indicator bins), dew point (in 5 degree Celsius indicator bins), wind speed (in $2.5 \mathrm{~m} / \mathrm{sec}$ indicator bins), air pressure (in $25 \mathrm{hPa}$ indicator bins) and ozone concentration (in $20 \mu \mathrm{g} / \mathrm{m}^{3}$ indicator bins). Weather indicators are daily averages, ozone is measured at the hour of kickoff. Match controls: day of week, kickoff time and stadium attendance indicators. Significance levels are $0.1(*), 0.05(* *)$, and $0.01(* * *)$. 
Table 6: Lagged effect of particulate matter on productivity and adaptation

\begin{tabular}{|c|c|c|c|c|c|c|}
\hline & \multirow{2}{*}{$\frac{\text { Pooled OLS }}{(1)}$} & \multicolumn{5}{|c|}{ Player fixed effects } \\
\hline & & $(2)$ & $(3)$ & $(4)$ & $(5)$ & $(6)$ \\
\hline $\ln (\mathrm{PM} 10)$ & $\begin{array}{c}-0.018^{* * *} \\
(0.003)\end{array}$ & $\begin{array}{c}-0.014^{* * *} \\
(0.002)\end{array}$ & $\begin{array}{c}-0.020^{* * *} \\
(0.003)\end{array}$ & $\begin{array}{c}-0.017^{* * *} \\
(0.003)\end{array}$ & $\begin{array}{c}-0.019^{* * *} \\
(0.003)\end{array}$ & $\begin{array}{c}-0.052^{* * *} \\
(0.015)\end{array}$ \\
\hline $\ln (\operatorname{lag}$ PM10) & $\begin{array}{c}0.004 \\
(0.004)\end{array}$ & $\begin{array}{c}-0.009^{* *} \\
(0.004)\end{array}$ & $\begin{array}{c}-0.008^{* *} \\
(0.004)\end{array}$ & $\begin{array}{c}-0.008^{* *} \\
(0.004)\end{array}$ & $\begin{array}{c}-0.010^{* * *} \\
(0.004)\end{array}$ & $\begin{array}{c}-0.041^{* * *} \\
(0.014)\end{array}$ \\
\hline $\ln ($ PM10 $) \times \ln (\operatorname{lag}$ PM10 $)$ & & & & & & $\begin{array}{c}0.010^{* *} \\
(0.005)\end{array}$ \\
\hline Player characteristics & Yes & Yes & Yes & Yes & Yes & Yes \\
\hline Weather and ozone controls & No & No & Yes & Yes & Yes & Yes \\
\hline Match controls & No & No & No & Yes & Yes & Yes \\
\hline Team $\times$ Season FE & No & No & No & No & Yes & Yes \\
\hline Observations & 70,203 & 70,203 & 70,203 & 70,203 & 70,203 & 70,203 \\
\hline Adjusted R-Squared & 0.772 & 0.747 & 0.747 & 0.748 & 0.754 & 0.754 \\
\hline
\end{tabular}

Note: Dependent variable: Log of passes. Player characteristics: age (squared), tenure (squared), position dummies, minutes played (squared). Weather and ozone controls: maximum temperature (in 5 degree Celsius indicator bins), precipitation (in $5 \mathrm{~mm} / \mathrm{m}^{2}$ indicator bins), dew point (in 5 degree Celsius indicator bins), wind speed (in 2.5 $\mathrm{m} / \mathrm{sec}$ indicator bins), air pressure (in $25 \mathrm{hPa}$ indicator bins) and ozone concentration (in $20 \mu \mathrm{g} / \mathrm{m}^{3}$ indicator bins). Weather indicators are daily averages, ozone is measured at the hour of kickoff. Match controls: day of week, kickoff time and stadium attendance indicators. Significance levels are $0.1\left(^{*}\right), 0.05\left({ }^{* *}\right)$, and $0.01\left(^{* * *}\right)$.

Table 7: Effect of particulate matter on productivity on team and match level

\begin{tabular}{|c|c|c|c|c|c|c|}
\hline & \multicolumn{3}{|c|}{ Team-level estimates } & \multicolumn{3}{|c|}{ Match-level estimates } \\
\hline & (1) & $(2)$ & (3) & (4) & (5) & (6) \\
\hline $\ln (\mathrm{PM} 10)$ & $\begin{array}{c}-0.027^{* * *} \\
(0.006)\end{array}$ & $\begin{array}{c}-0.015^{* * *} \\
(0.006)\end{array}$ & $\begin{array}{c}-0.017^{* * *} \\
(0.006)\end{array}$ & $\begin{array}{c}-0.027^{* * *} \\
(0.005)\end{array}$ & $\begin{array}{c}-0.015^{* * *} \\
(0.005)\end{array}$ & $\begin{array}{c}-0.016^{* * *} \\
(0.005)\end{array}$ \\
\hline Weather and ozone controls & Yes & Yes & Yes & Yes & Yes & Yes \\
\hline Match controls & No & Yes & Yes & No & Yes & Yes \\
\hline Player controls on team level & No & No & Yes & No & No & No \\
\hline Player controls on match level & No & No & No & No & No & Yes \\
\hline Season FE & No & Yes & Yes & No & Yes & Yes \\
\hline Observations & 5,912 & 5,912 & 5,912 & 2,956 & 2,956 & 2,956 \\
\hline Adjusted R-Squared & 0.007 & 0.062 & 0.151 & 0.023 & 0.193 & 0.197 \\
\hline
\end{tabular}

Note: Dependent variable: Log of passes. Player characteristics: mean age and mean tenure of players by team (columns (1) to (3)) or match (columns (4) to (6)). A home dummy is also included. Weather and ozone controls: maximum temperature (in 5 degree Celsius indicator bins), precipitation (in $5 \mathrm{~mm} / \mathrm{m}^{2}$ indicator bins), dew point (in 5 degree Celsius indicator bins), wind speed (in $2.5 \mathrm{~m} / \mathrm{sec}$ indicator bins), air pressure (in $25 \mathrm{hPa}$ indicator bins) and ozone concentration (in $20 \mu \mathrm{g} / \mathrm{m}^{3}$ indicator bins). Weather indicators are daily averages, ozone is measured at the hour of kickoff. Match controls: day of week, kickoff time, stadium attendance indicators, number of goals. Significance levels are $0.1(*), 0.05(* *)$, and $0.01(* * *)$. 


\section{A Appendix}

Figure A.1: Match schedule distribution across months, weekdays and time
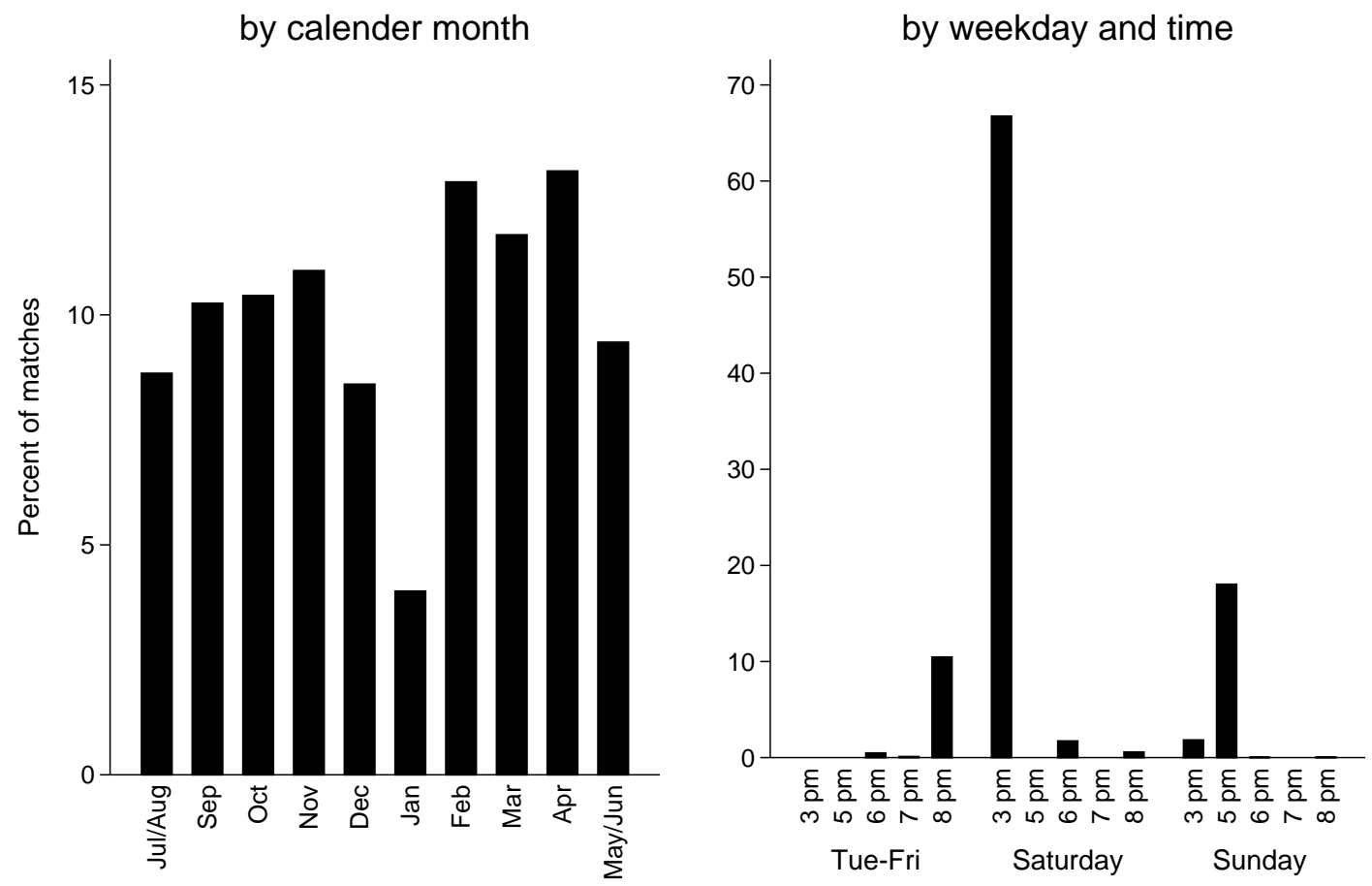

Note: This graph shows bar charts visualizing the distribution of matches by calender month (left panel), and weekdays and time of the day (right panel). Matches in July and June are merged with August and May respectively, since only very few matches were held during the two summer months. 
Figure A.2: Variation of particulate matter over time for selected stadiums
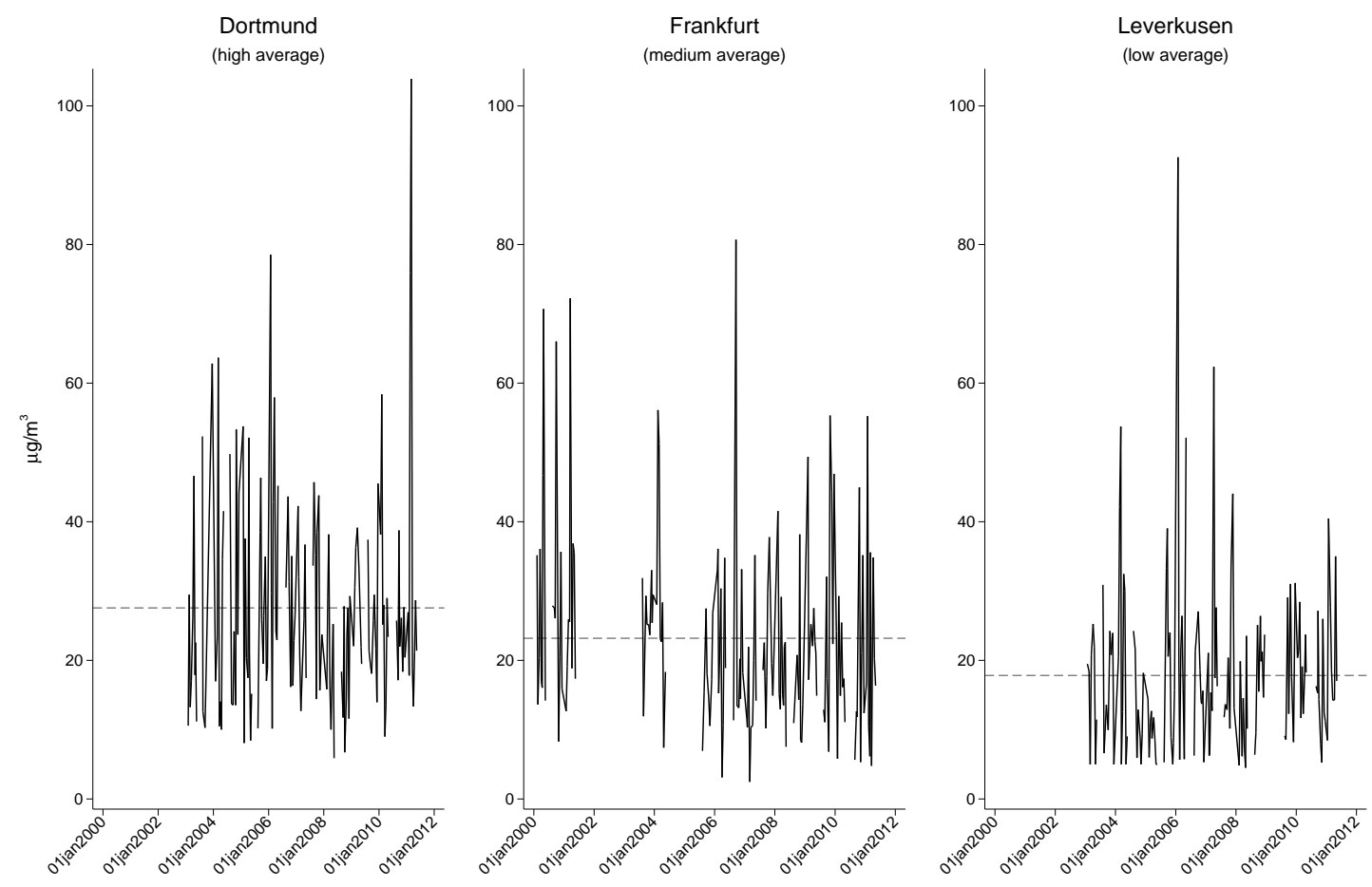

Note: This graph plots of the variation in particulate matter PM10 over time for three selected stadiums representing locations with pollution values which are on average high (Dortmund, left panel), medium (Frankfurt, middle panel) and low (Leverkusen, right panel). The dashed lines indicate the respective mean values over all available match observations. Missing data points are either due to team absence from the Bundesliga or non-availability of pollution monitors in proximity to the stadium. 
Figure A.3: Non-linear effect of particulate matter on productivity

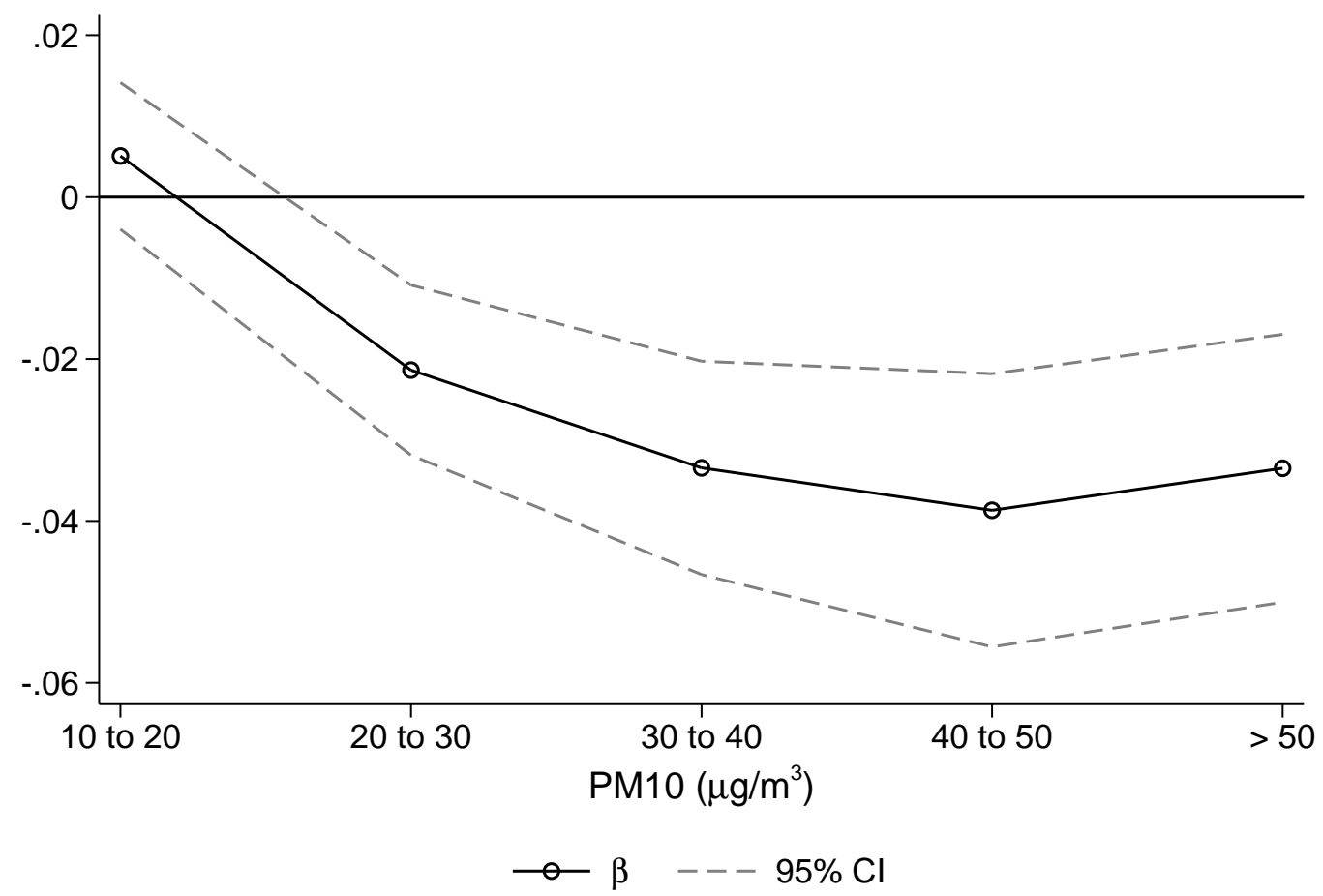

Note: This graph shows the marginal effect of PM10 and the $95 \%$ confidence interval for bins of $10 \mu \mathrm{g} / \mathrm{m}^{3}$. Baseline category: 0 to $10 \mu \mathrm{g} / \mathrm{m}^{3}$. The underlying specification is equation (1), substituting the constant effect by bin dummies. 
Table A.1: Effect of particulate matter on productivity: log-linear specification

\begin{tabular}{|c|c|c|c|c|c|c|}
\hline & \multirow{2}{*}{$\frac{\text { Pooled OLS }}{(1)}$} & \multicolumn{5}{|c|}{ Player fixed effects } \\
\hline & & $(2)$ & $(3)$ & $(4)$ & $(5)$ & (6) \\
\hline PM10/100 & $\begin{array}{c}-0.077^{* * *} \\
(0.010)\end{array}$ & $\begin{array}{c}-0.064^{* * *} \\
(0.010)\end{array}$ & $\begin{array}{c}-0.081^{* * *} \\
(0.011)\end{array}$ & $\begin{array}{c}-0.077^{* * *} \\
(0.011)\end{array}$ & $\begin{array}{c}-0.091^{* * *} \\
(0.012)\end{array}$ & $\begin{array}{c}-0.076^{* * *} \\
(0.012)\end{array}$ \\
\hline Player characteristics & Yes & Yes & Yes & Yes & Yes & Yes \\
\hline Weather and ozone controls & No & No & Yes & Yes & Yes & Yes \\
\hline Match controls & No & No & No & Yes & Yes & Yes \\
\hline Team $\times$ Season FE & No & No & No & No & Yes & Yes \\
\hline Stadium FE & No & No & No & No & No & Yes \\
\hline Observations & 75,163 & 75,163 & 75,163 & 75,163 & 75,163 & 75,163 \\
\hline Adjusted R-Squared & 0.770 & 0.746 & 0.746 & 0.747 & 0.753 & 0.756 \\
\hline
\end{tabular}

Note: Dependent variable: Log of passes. Player characteristics: age (squared), tenure (squared), position dummies, minutes played (squared). Weather and ozone controls: maximum temperature (in 5 degree Celsius indicator bins), precipitation (in $5 \mathrm{~mm} / \mathrm{m}^{2}$ indicator bins), dew point (in 5 degree Celsius indicator bins), wind speed (in 2.5 $\mathrm{m} / \mathrm{sec}$ indicator bins), air pressure (in $25 \mathrm{hPa}$ indicator bins) and ozone concentration (in $20 \mathrm{\mu g} / \mathrm{m}^{3}$ indicator bins). Weather indicators are daily averages, ozone is measured at the hour of kickoff. Match controls: day of week, kickoff time and stadium attendance indicators. Significance levels are $0.1\left(^{*}\right), 0.05(* *)$, and $0.01(* * *)$.

Table A.2: Effect of particulate matter on other outcomes

\begin{tabular}{|c|c|c|c|c|c|}
\hline \multirow[t]{2}{*}{ Dependent variable: } & $\begin{array}{l}\text { Minutes } \\
\text { played }\end{array}$ & $\begin{array}{l}\text { Playing } \\
\text { full length }\end{array}$ & $\begin{array}{l}\text { Short } \\
\text { passes }\end{array}$ & $\begin{array}{c}\text { Pass } \\
\text { accuracy }\end{array}$ & $\begin{array}{l}\text { Pass ratio } \\
\text { (long/short) }\end{array}$ \\
\hline & (1) & (2) & (3) & (4) & (5) \\
\hline $\ln (\mathrm{PM} 10)$ & $\begin{array}{c}0.011 \\
(0.158)\end{array}$ & $\begin{array}{c}0.001 \\
(0.003)\end{array}$ & $\begin{array}{c}-0.021^{* * *} \\
(0.004)\end{array}$ & $\begin{array}{c}-0.002^{* * *} \\
(0.001)\end{array}$ & $\begin{array}{c}0.003^{* * *} \\
(0.001)\end{array}$ \\
\hline Player characteristics & Yes & Yes & Yes & Yes & Yes \\
\hline Weather and ozone controls & Yes & Yes & Yes & Yes & Yes \\
\hline Match controls & Yes & Yes & Yes & Yes & Yes \\
\hline Team $\times$ Season FE & Yes & Yes & Yes & Yes & Yes \\
\hline Observations & 75,163 & 75,163 & 75,163 & 73,832 & 73,718 \\
\hline Adjusted R-Squared & 0.064 & 0.045 & 0.675 & 0.023 & 0.034 \\
\hline
\end{tabular}

Note: Player characteristics: age (squared), tenure (squared), position dummies, minutes played (squared). Weather and ozone controls: maximum temperature (in 5 degree Celsius indicator bins), precipitation (in $5 \mathrm{~mm} / \mathrm{m}^{2}$ indicator bins), dew point (in 5 degree Celsius indicator bins), wind speed (in $2.5 \mathrm{~m} / \mathrm{sec}$ indicator bins), air pressure (in $25 \mathrm{hPa}$ indicator bins) and ozone concentration (in $20 \mathrm{\mu g} / \mathrm{m}^{3}$ indicator bins). Weather indicators are daily averages, ozone is measured at the hour of kickoff. Match controls: day of week, kickoff time and stadium attendance indicators. Significance levels are $0.1(*), 0.05(* *)$, and $0.01(* * *)$. 